\title{
SOME INEQUALITIES FOR THE VOLUME OF THE UNIT BALL
}

\section{Yin AND LI-GUO HUANG}

Abstract. In the paper, the authors establish some new inequalities involving the volume of the unit ball in $\mathbb{R}^{n}$ and refine some results of Alzer.

Mathematics subject classification (2010): 33B15, 41A10, 42A16.

Keywords and phrases: Volume of the unit $n$-dimensional ball, gamma function, Legendre formula, inequalities.

\section{REFERENCES}

[1] M. Abramovitz And I. A. STegun, Handbook of mathematical functions with formulas, Graphs, and Mathematical Tables, Dover Publ. New York (1970).

[2] H. AlzER, Inequalities for the volume of the unit ball in $\mathbb{R}^{n}$, J. Math. Anal. Appl. 252 (2000), 353363. http://dx.doi.org/10.1006/jmaa.2000.7065

[3] H. AlzER, Inequalities for the volume of the unit ball in $\mathbb{R}^{n}$, II, Mediterr. J. Math. 5 (2008), no. 4, 395-413. http://dx.doi.org/10.1007/s00009-008-0158-x

[4] H. AlzER, On some inequalities for the gamma and psi functions, Math. Comput. 66 (1997), 373-389. http://dx.doi.org/10.1090/S0025-5718-97-00814-4

[5] G. D. ANDERSON AND S. L. QIU, A monotonicity property of the gamma function, Proc. Amer. Math. Soc. 125 (1997), 3355-3362. http://dx.doi.org/10.1090/S0025-5718-97-00814-4

[6] G. D. Anderson, M. K. Vamanamurthy AND M. Vuorinen, Special functions of quasiconformal theory, Expo. Math. 7 (1989), 97-136.

[7] K. H. BorgWardT, The simplex method, Springer, Berlin, (1981).

[8] C.-P. Chen AND L. Lin, Inequalities for the volume of the unit ball in $\mathbb{R}^{n}$, Mediterr. J. Math. 11 (2014), no. 2, 299-314. http://dx.doi.org/10.1007/s00009-013-0340-7

[9] B.-N. GUO AND F. QI, A class of completely monotonic functions involving devided differences of the psi and tri-gamma functions and some applications, J. Korean Math. Soc. 48 (2011), no. 3, 655-667. http://dx.doi.org/10.4134/JKMS.2011.48.3.655

[10] B.-N. GUO AND F. QI, Monotonicity and logarithmic convexity relating to the volume of the unit ball, Optim. Lett. 7 (2013), no. 6, 1139-1153. http://dx.doi .org/10.1007/s11590-012-0488-2

[11] D. A. KLAin ANd G. C. Rota, A continuous analogue of Sperner's theorem, Commun. Pure Appl. Math. 50 (1997), no. 3, 205-223. http://dx.doi.org/10.1002/(SICI) 1097-0312(199703) 50: 3<205: : AID-CPA1>3.0.CD;2-F

[12] D. S. Mitrinovic, Analytic inequalities, Springer-verlag, New York, 1970.

[13] C. MoRTICI, Monotonicity property of the volume of the unit ball in $\mathbb{R}^{n}$, Optim. Lett. 4 (2010), no. 3, 457-464. http://dx.doi.org/10.1007/s11590-009-0173-2

[14] C. MoRTICI, On Gosper formula for the gamma function, J. Math. Inequal. 5 (2011), no. 4, 611-614. http://dx.doi.org/10.7153/jmi-05-53

[15] F. QI, C.-F. WEI, AND B.-N. GUO, Complete monotonicity of a function involving the ratio of gamma functions and applications, Banach J. Math. Anal. 6 (2012), no. 1, 35-44. http://dx.doi.org/ 10.15352/bjma/1337014663

[16] S.-L. QIU AND M. Vuorinen, Some properties of the gamma and psi functions, with applications, Math. Comput. 74 (2004), no. 250, 723-742. http://dx.doi.org/10.1090/S0025-5718-04 $-01675-8$

[17] L. YIN, Several inequalities for the volume of the unit ball in $\mathbb{R}^{n}$, Bull. Malaysian Math. Sci. Soc. 37 (2014), no. 4, 1177-1183. 
[18] J.-L. ZhaO, B.-N. GUO, AND F. QI, A refinement of a double inequality for the gamma functions, Publ. Math. Debrecen 80 (2012), no. 3-4, 333-342. http://dx.doi.org/10.5486/PMD. 2012.5010 